\title{
Comparison of General and Local Anesthesia for Deep Brain Stimulator Insertion: A Systematic Review
}

\author{
Veena Sheshadri, Nathan C. Rowland, Jigesh Mehta, Marina Englesakis, \\ Pirjo Manninen, Lashmi Venkatraghavan
}

\begin{abstract}
Background: Subthalamic nucleus deep brain stimulation (STN-DBS) has become a standard treatment for many patients with Parkinson's disease (PD). The reported clinical outcome measures for procedures done under general anesthesia (GA) compared to traditional local anesthetic (LA) technique are quite heterogeneous and difficult to compare. The aim of this systematic review and metaanalysis was to determine whether the clinical outcome after STN-DBS insertion under GA is comparable to that under LA in patients with Parkinson's disease. Methods: The databases of Medline Embase, Cochrane library and Pubmed were searched for eligible studies (human trials, English language, published between 1946 and January of 2016). The primary outcome of this study was to assess the postoperative improvement in the symptoms, evaluated using either Unified Parkinson's Disease Rating Scale (UPDRS) scores or levodopa equivalent dosage (LEDD) requirement. Results: The literature searches yielded 395 citations and six retrospective cohort studies with a sample size of 455 (194 in GA and 261 in LA) were included in the analysis. Regarding the clinical outcomes, there were no significant differences in the postoperative Unified Parkinson's disease rating scale and levodopa equivalent drug dosage between the GA and the LA groups. Similarly, the adverse events and target accuracy were also comparable between the groups. Conclusions: This systematic review and meta-analysis shows that currently there is no good quality data to suggest equivalence of GA to LA during STN-DBS insertion in patients with PD, with some factors trending towards LA. There is a need for a prospective randomized control trial to validate our results.
\end{abstract}

RÉSUMÉ: Comparaison entre l'anesthésie générale etl'anesthésie locale lors de l'implantation d'un appareil de stimulation cérébrale profonde. Contexte: La stimulation cérébrale profonde du noyau sous-thalamique est maintenant le traitement standard chez plusieurs patients atteints de la maladie de Parkinson (MP). Les résultats cliniques consécutifs à des interventions chirurgicales effectuées sous anesthésie générale (AG) ou à la technique traditionnelle d'intervention sous anesthésie locale $(\mathrm{AL})$ sont très hétérogènes et difficiles à comparer entre eux. Le but de cette revue systématique et de cette méta-analyse a donc été de déterminer siles résultats cliniquesaprès l'implantation sous AG d'un appareil de stimulation cérébrale profonde sont comparables à ceux consécutifs à une implantation effectuée sous AL chez des patients atteints de la MP. Méthodes: Nous avons interrogé les bases de données Medline et Embase, ainsi que celles de la Cochrane Library et de PubMed, afin d'identifier des études admissibles (effectuées à partir d'essais cliniques portant sur des êtres humains ; rédigées en anglais ; publiées entre 1946 et janvier 2016). Le principal objectif de cette étude a été d'évaluer, soit au moyen de la Unified Parkinson's Disease Rating Scale ou au moyen d'une dose équivalente en lévodopa, les améliorations post-opératoires des symptômes. Résultats: Notre recherche documentaire nous a permis d'identifier 395 citations et six études de cohortes rétrospectives totalisant 455 sujets (194 sous AG et 261 sous AL), lesquelles ont toutes été incluses dans notre analyse. En ce qui a trait à nos résultats cliniques, aucune différence notable n'a été observée entre le groupe AG et le groupe AL quant aux scores postopératoires à la Unified Parkinson's Disease Rating Scale et à la dose équivalente en lévodopa. De plus, tant l'incidence d'événements indésirables que l'exactitude des résultat visés se sont révélées comparables d'un groupe à l'autre. Conclusions: Cette revue systématique et cette méta-analyse ont ainsi démontré qu'il n'existe pas actuellement des données probantes suggérant une équivalence entre l'AG et l'AL lors de l'implantation, pour des patients atteints de la MP, d'un appareil de stimulation cérébrale profonde du noyau sous-thalamique. Certains facteurs tendent néanmoins à favoriser l'AL. Une étude prospective contrôlée et randomisée serait donc nécessaire pour valider nos résultats.

Keywords: Parkinson's disease, deep brain stimulation, subthalamic nucleus, general anesthesia, local anesthesia, clinical outcomes, Unified Parkinson's Disease Rating Scale, Levodopa equivalent drug dosage, adverse events, microelectrode recording

doi:10.1017/cjn.2017.224

Can J Neurol Sci. 2017; 44: 697-704

\section{BACKGROUND}

Subthalamic nucleus deep brain stimulator (STN-DBS) insertion has become one of the standard forms of treatment for patients with advanced Parkinson's disease (PD). ${ }^{1}$ Clinical outcome after
DBS insertion depends on careful patient selection and precise target localization. Common methods for target localization include brain imaging with a stereotactic headframe and intraoperative neurophysiological mapping with microelectrode recording (MER)

From the Department of Anesthesia, Toronto Western Hospital, University of Toronto, Toronto, Ontario, Canada (VS, JM, PM, LV); the Department of Stereotactic and Functional

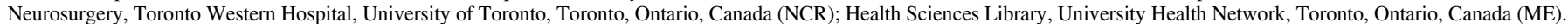
Received November 14, 2016. Final Revisions Submitted May 5, 2017. Date of Acceptance May 28, 2017.

Correspondence to: Lashmi Venkatraghavan, Department of Anesthesia, Toronto Western Hospital, 399 Bathurst Street, Toronto, Ontario M5T 258, Canada. Email: Lashmi.

Venkatraghavan@uhn.ca. 
and macrostimulation. ${ }^{2}$ Due to the effects of anesthetic agents on MER and the need for an awake patient for stimulation testing, local anesthesia (LA) with or without sedation has been the standard anesthetic technique for DBS insertion at many centers. ${ }^{2,3}$ However, some patients with claustrophobia or those with severe symptoms may not be able to tolerate this procedure under LA with sedation and often need general anesthesia (GA). ${ }^{4}$ In addition, with advances in imaging, both target localization and placement of DBS electrodes have also been performed under GA using intraoperative magnetic resonance imaging (iMRI) guidance without the need for neurophysiological testing. ${ }^{5-7}$ Though many studies have reported successful clinical outcomes with DBS insertion under GA, the reported outcome measures are quite heterogeneous and difficult to compare with the procedures done under LA. ${ }^{4,8-11}$ Currently, there are limited data in the literature comparing clinical outcomes after DBS insertion under GA and LA.

The objective of this systematic review and metaanalysis was to determine whether or not the clinical outcomes following STN-DBS insertion under GA are comparable to those under LA in patients with Parkinson's disease. The outcome measures included postoperative improvement in symptoms, accuracy of target placement, and procedure-related adverse events.

\section{MeTHODS}

This systematic review and metaanalysis was conducted and reported according to the Preferred Reporting Items for Systematic Reviews and Meta-Analyses - the PRISMA Statement. ${ }^{12}$ The PRISMA checklist is available as electronic supplementary material (presented as a table that illustrates the PRISMA checklist; see Supplemental Digital Content 1).

\section{Search Strategy}

The databases of Medline (Ovid) (1946 to week 2 of January of 2016), Medline In-Process, and other nonindexed citations (Ovid) (22 January 2016), Embase (Ovid) (1947 to 22 January 2016), the Cochrane Central Register of Controlled Trials (CENTRAL) (December of 2015), the Cochrane Database of Systematic Reviews (CDSR) in the Cochrane Library (2005 to 2nd quarter of 2015), and PubMed (not Medline) (1945 to 24 January 2016) were searched by a professional librarian, and the procedure was reviewed by two independent authors (VS and JM). Searches were conducted using two different components: (1) deep brain stimulation and anesthesia, and (2) Parkinson's disease, effectiveness, or prognosis. The keywords used in the Medline and other searches included deep brain stimulation, electrical stimulation therapy, implantable neurostimulators, prostheses and implants, electrodes, anesthesia, conscious sedation, analog sedation, anesthetics or sedatives, isoflurane, sevoflurane, desflurane, propofol, fentanyl, midazolam, dexmedetomidine, Lewy body disease, essential tremors, Parkinson's disease, paralysis agitans, experimental epidemiological studies, mortality, morbidity, randomized controlled trials, cohort studies, longitudinal studies, double blind, effectiveness, and prognosis. The more detailed search strategy is available as electronic supplementary material (presented as a table that illustrates the search strategy; see Supplemental Digital Content 2).

A search of trial registries and a manual search of the reference lists from the selected articles were conducted to identify additional trials. The authors of eligible studies were contacted by email for missing data. The search was restricted to the English language and only human studies.

\section{Study Eligibility}

The search results were evaluated by two independent reviewers (VS, JM), and studies eligible for probable inclusion were identified using predefined selection criteria. Any disagreements between authors were resolved via discussion or in consultation with the senior author (LV). Our inclusion criteria included studies comparing the clinical outcome of bilateral STN-DBS insertion under GA and LA with or without sedation in patients with PD. Our exclusion criteria included: (1) DBS insertion for movement disorders other than PD; (2) studies where reported outcomes were not separated by type of anesthesia; (3) case reports and review articles; (4) noncomparative studies (i.e., studies with only one group-GA or LA); and (5) studies comparing sedation versus no sedation.

\section{Study Selection and Methodological Quality Assessment}

In the first phase of the review, discernibly irrelevant articles were excluded from the search results by reviewing the title and abstracts. In the next phase, the full-text articles were evaluated to determine whether they met the eligibility criteria. Studies eligible for the qualitative review were selected and further evaluated for quantitative analysis. The studies eligible for quantitative analysis with similar outcome measures were pooled for the metaanalysis. The follow-up periods for the primary outcome measure ranged from 3 to 12 months.

Two independent reviewers (VS, NCR) assessed the quality of the studies, and any disagreements between them were resolved by discussion with the senior author (LV). Quality assessment of the studies was performed using the Newcastle-Ottawa Scale. ${ }^{13}$ This tool has been used for assessing the quality of cohort or nonrandomized studies included in systematic reviews and/or metaanalyses. Each study is judged on eight items categorized into three groups: (1) selection of study groups, (2) comparability of study groups, and (3) ascertainment of the outcome of interest. One star is awarded for each quality item, four stars constitute the maximum for selection of groups, two stars the maximum for comparability, and three stars the maximum for ascertainment of outcome. The highest-quality studies are awarded a maximum of nine stars.

\section{Data Extraction and Synthesis}

Data extraction was performed by two reviewers and validated by the senior author. The extracted data included study design, sample size, characteristics of the study population, preoperative condition of the patient, dose of levodopa, method used for target planning, intraoperative localization and final electrode position, microelectrode recording (MER), stimulation intensity, details of anesthetic management, operative time, and, finally, outcome measures from individual studies.

\section{Outcome Measures}

The primary outcome of our study was to assess postoperative improvement in terms of symptoms, evaluated using either Unified Parkinson's Disease Rating Scale (UPDRS) scores or levodopa equivalent daily dosage (LEDD) requirements. 
The UPDRS is a widely used four-part measure of impairment and disability associated with PD: Part I-nonmotor experiences of daily living; Part II-motor experiences of daily living; Part III-motor examination; and Part IV-motor complications. ${ }^{14}$ It has 65 items, with a possible total of 260 points. Higher scores indicate greater disability (260 represents worst disability and 0 no disability). The postoperative UPDRS part III scores with DBS on/off and medication on/off states were compared with the baseline medication-off scores from the preoperative period. ${ }^{15}$ The LEDD in $\mathrm{mg}$ /day was calculated for each antiparkinsonian medication by multiplying the total daily dosage of each drug by its potency relative to a standard levodopa/decarboxylase inhibitor (DCI) preparation (has a value of 1). ${ }^{16}$ The reduction in postoperative requirements suggested a good clinical outcome. The other outcome measures were accuracy in target placement of the DBS electrode and adverse events associated with the procedure.

\section{Data Analysis}

The effect sizes were expressed either as estimates of the odds ratio (OR) for dichotomous variables or as the standard mean difference (SMD) for continuous variables. When necessary, the standard deviation (SD) was estimated based on the reported 95\% confidence interval $\left(\mathrm{CI}_{95 \%}\right)$ limits, standard error, or range values. Data from the selected studies were combined to estimate the pooled effect of GA and LA. For each outcome measure, pooled estimates and $95 \%$ confidence intervals were calculated by using an inverse variance random-effects approach. A random-effects model was utilized in all analyses because of the few eligible studies and the smaller sample sizes. ${ }^{17}$ Heterogeneity was measured using $I^{2}$ statistics. ${ }^{18}$ Sensitivity analyses were performed if deemed necessary to explain the heterogeneity. We did not test for publication bias or small-study effects due to the small number of studies included in this analysis. A value of $p<0.05$ was considered statistically significant. Metaanalyses were performed using Review Manager (RevMan, v. 5.3, The Nordic Cochrane Centre, The Cochrane Collaboration, Copenhagen, 2014).

\section{RESULTS}

\section{Literature Search and Baseline Characteristics of Included Studies}

The initial search strategy yielded 395 citations (Figure 1). After screening the titles and abstracts, 365 studies that did not meet the eligibility criteria were excluded. The remaining 30 studies were included for full-text review. From this, 24 studies were excluded for the following reasons: only one group (GA or LA) with no control (14), compared sedation with no sedation (7), and nonrelevant outcome measures (3). In the end, six studies were considered for qualitative review and metaanalysis. All the included studies were retrospective cohort studies. Study demographics and baseline disease characteristics are given in Table 1. The total number of subjects in our study was 455 (194 in the GA group and 261 in the LA group).
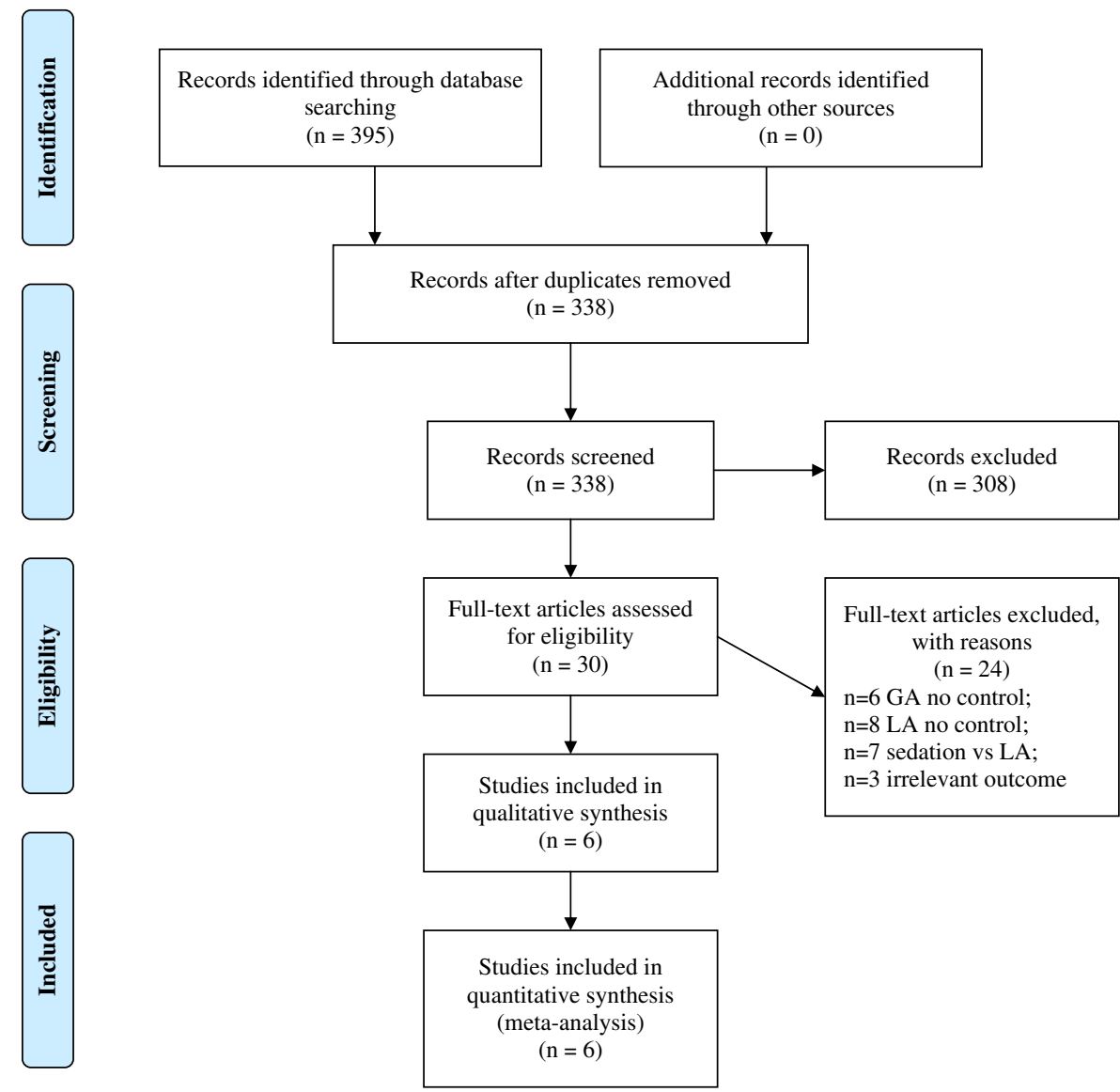

Figure 1: PRISMA 2009 flow diagram. 
Table 1: Study demographics and baseline disease characteristics

\begin{tabular}{|c|c|c|c|c|c|c|c|c|c|}
\hline $\begin{array}{l}\text { First author, } \\
\text { year }\end{array}$ & $\begin{array}{l}\text { Study } \\
\text { design }\end{array}$ & $\begin{array}{l}\text { Sample } \\
\text { size }(n)\end{array}$ & $\begin{array}{c}\text { GA } \\
\text { LA }(n)\end{array}$ & $\begin{array}{c}\text { Age } \\
\text { (GA, LA) } \\
\text { (years) }\end{array}$ & $\begin{array}{l}\text { Sex } \\
(\% \mathbf{M})\end{array}$ & $\begin{array}{c}\text { Disease } \\
\text { duration } \\
\text { (GA, LA) } \\
\text { (years) }\end{array}$ & $\begin{array}{c}\text { Levodopa dose } \\
\text { (GA, LA) } \\
\text { (mg/day) }\end{array}$ & $\begin{array}{c}\text { Response to } \\
\text { levodopa (mean \% } \\
\text { improvement in } \\
\text { UPDRS, GA vs. LA) }\end{array}$ & $\begin{array}{l}\text { Baseline } \\
\text { UPDRS }\end{array}$ \\
\hline $\begin{array}{l}\text { Yamada, } \\
2007^{16}\end{array}$ & $\mathrm{R}$ & 25 & $\begin{array}{l}15 \\
10\end{array}$ & $\begin{array}{l}65.2 \pm 7.0 \\
65.6 \pm 8.6\end{array}$ & 36 & $\begin{array}{r}11.1 \pm 5.0 \\
6.8 \pm 2.4^{*}\end{array}$ & $\begin{array}{r}375.7 \pm 195.6 \\
425 \pm 171.83\end{array}$ & $\begin{array}{l}41.98 \\
37.47\end{array}$ & $\begin{array}{l}52.4 \pm 19 \\
45.9 \pm 17.7\end{array}$ \\
\hline $\begin{array}{l}\text { Lefaucheur, } \\
2008^{19}\end{array}$ & $\mathrm{R}$ & 54 & $\begin{array}{l}30 \\
24\end{array}$ & $\begin{array}{l}57.7 \pm 11.1 \\
61.2 \pm 8.1\end{array}$ & 62.9 & $\begin{array}{l}14.0 \pm 4.0 \\
14.4 \pm 4.8\end{array}$ & $\begin{array}{r}1470.8 \pm 729.5 \\
1642 \pm 1048.8\end{array}$ & NA & $\begin{array}{l}47.9 \pm 13.6 \\
48.6 \pm 19\end{array}$ \\
\hline Chen, $2011^{20}$ & $\mathrm{R}$ & 52 & $\begin{array}{l}33 \\
19\end{array}$ & $\begin{array}{l}59.85 \pm 8.79 \\
53.79 \pm 13.39\end{array}$ & NA & $\begin{array}{r}9.30 \pm 3.51 \\
10.47 \pm 6.20\end{array}$ & $\begin{array}{r}972.37 \pm 441.74 \\
849.9 \pm 313.81\end{array}$ & $\begin{array}{l}44.63 \\
43.4\end{array}$ & $\begin{array}{l}47.67 \pm 14.83 \\
46.05 \pm 13.13\end{array}$ \\
\hline $\begin{array}{l}\text { Nakajima, } \\
2011^{21}\end{array}$ & $\mathrm{R}$ & 82 & $\begin{array}{l}14 \\
68\end{array}$ & $\begin{array}{l}56.1 \pm 6.5 \\
57.5 \pm 7.0\end{array}$ & 64.6 & $\begin{array}{l}13.8 \pm 8.1 \\
15.2 \pm 8.1\end{array}$ & $\begin{array}{l}1505 \pm 764 \\
1338 \pm 680\end{array}$ & $\begin{array}{r}65 \\
72.5\end{array}$ & $\begin{array}{l}57.9 \pm 16.6 \\
48.1 \pm 15.7\end{array}$ \\
\hline $\begin{array}{l}\text { Sutcliffe, } \\
2011^{22}\end{array}$ & $\mathrm{R}$ & 46 & $\begin{array}{l}26 \\
20\end{array}$ & $\begin{array}{l}58.0 \pm 7.17 \\
56.3 \pm 7.05\end{array}$ & 71.7 & $\begin{array}{r}8.9 \pm 3.96 \\
10.9 \pm 4.27\end{array}$ & $\begin{array}{l}1927 \pm 891 \\
1728 \pm 859\end{array}$ & NA & NA \\
\hline Saleh, $2015^{23}$ & $\mathrm{R}$ & 37 & $\begin{array}{l}14 \\
23\end{array}$ & $\begin{array}{l}64.0 \pm 11.9 \\
60.6 \pm 7.0\end{array}$ & 56.7 & $\begin{array}{l}10.9 \pm 3.8 \\
11.3 \pm 4.9\end{array}$ & $\begin{array}{l}1,702.7 \pm 876 \\
2,134.9 \pm 1,175\end{array}$ & NA & NA \\
\hline
\end{tabular}

Values are presented as means \pm standard deviations.

${ }^{*} p<0.05$.

$\mathrm{NA}=$ not available; $\mathrm{R}=$ retrospective; $\mathrm{UPDRS}=$ Unified Parkinson's Disease Rating Scale.

\section{Quality Assessment}

All the included studies had at least seven stars on the Newcastle-Ottawa Scale. A summary of the included studies is presented in Table 2. Detailed quality-assessment analysis is available as electronic supplementary material (in the form of a table that illustrates detailed assessment using the NewcastleOttawa Scale; see Supplementary Digital Content 3).

\section{Anesthesia}

The details of the anesthetic regimen and the drugs used are given in Table 3. In the GA group, the details on anesthetics were reported in four studies, consisting of intravenous induction and endotracheal intubation followed by maintenance of anesthesia with an inhalational agent. In the LA group, two studies reported procedural sedation, in one study propofol was used for brief period, and moderate sedation was employed during most of the other studies.

\section{Target Planning and Localization}

MRI was used for preoperative target planning in all of the studies, and, in addition, ventriculography was utilized in two studies. ${ }^{16,19}$ Intraoperative target localization was either by an image-guided technique, as performed by Nakajima et al. ${ }^{21}$ and Saleh et al. ${ }^{23}$ (GA group), or combined imaging (either based on preoperative MRI or direct intraoperative imaging) and MER technique. General anesthesia did not affect the MER and localization of STN, and the MER was successful in all patients in four studies. ${ }^{16,19,20,22}$ Intraoperative macrostimulation was performed in all studies from the LA group. Three studies reported postoperative confirmation of electrode location with either computerized tomography (CT) or MRI. ${ }^{20,21,23}$ Postoperative stimulation parameters were not significantly different between groups in four studies. ${ }^{16,19-21}$

\section{Clinical Outcomes}

The primary outcome measures included in this metaanalysis were UPDRS score ${ }^{16,20,21}$ and LEDD requirement. ${ }^{16,20-23}$ Though another study ${ }^{19}$ also reported UDPRS score and LEDD requirement as outcome measures, the data were reported as percentage reduction instead of absolute values, and it was thus not possible to include this study in the pooled analysis. Adverse events included in the metaanalysis were those related to general surgical and neurological events, as well as stimulation-induced and hardware-related side effects.

Table 2: Assessment of the quality of the included studies using the Newcastle-Ottawa Scale

\begin{tabular}{|c|c|c|c|c|c|}
\hline First author, year & GA $(n)$ & LA (n) & Selection & Comparability & Outcome \\
\hline Yamada, $2007^{16}$ & 15 & 10 & $\star \star \star \star$ & $\star \star$ & $\star \star \star$ \\
\hline Lefaucheur, $2008^{19}$ & 30 & 24 & $\star \star \star \star$ & $\star \star$ & $\star \star \star$ \\
\hline Chen, $2011^{20}$ & 33 & 19 & $\star \star \star \star$ & $\star \star$ & $\star \star$ \\
\hline Nakajima, $2011^{21}$ & 14 & 68 & $\star \star \star \star$ & $\star$ & $\star \star$ \\
\hline Sutcliffe, $2011^{22}$ & 26 & 20 & $\star \star \star \star$ & $\star$ & $\star \star$ \\
\hline Saleh, $2015^{23}$ & 14 & 23 & $\star \star \star \star$ & $\star$ & $\star \star$ \\
\hline
\end{tabular}

One star is awarded for each quality item. Four stars are the maximum for selection of groups, two stars the maximum for comparability, and three stars the maximum for ascertainment of the outcome. 
Table 3: Details of anesthesia

\begin{tabular}{l|l|l|l|l}
\hline First author, year & LA with sedation & Anesthesia induction & Intubation/maintenance & Operative times (h) \\
\hline Yamada, $2007^{16}$ & No sedation & Fentanyl, propofol & ETT/ $_{2}, \mathrm{~N}_{2} \mathrm{O}+$ sevoflurane 0.7-1.2 MAC & NA \\
\hline Lefaucheur, $2008^{19}$ & No sedation & NA & NA & $5-7$ \\
\hline Chen, $2011^{20}$ & Propofol & Narcotics, muscle relaxants & ETT/desflurane 0.5-1 MAC & $4-6$ in both groups \\
\hline Nakajima, $2011^{21}$ & No sedation & Midazolam, fentanyl, propofol & ETT/sevoflurane MAC 1, remifentanil infusion & $<2 \mathrm{GA},<3 \mathrm{LA}$ \\
\hline Sutcliffe, $2011^{22}$ & No sedation & Fentanyl, propofol, atracurium & ETT/ $\mathrm{N}_{2} \mathrm{O}$, isoflurane & 7.2-7.8 GA vs. 7.8-8.6 LA \\
\hline Saleh, $2015^{23}$ & Sedation & NA & ETT/NA & 7.43-13.33 GA vs. 4.36-10.04 LA \\
\hline
\end{tabular}

$\mathrm{ETT}=$ endotracheal tube $\mathrm{MAC}=$ minimum alveolar concentration $; \mathrm{NA}=$ not available.

Postoperative UDPRS III scores after DBS insertion under GA were not statistically different compared to the procedure done under LA $\left(p=0.09, S M D=0.32, C I_{95 \%}=-0.05\right.$ to 0.68$)$. There was no heterogeneity among the studies $\left(I^{2}=0 \%, \tau^{2}=0\right.$, $\chi^{2}=0.41$ ) (Figure 2).

Similarly, no significant differences were found in postoperative LEDD requirements between DBS insertion under GA and LA ( $p=0.84, S M D=0.03, C I_{95 \%}=-0.26$ to 0.32 ), and there was no significant heterogeneity among the studies $\left(I^{2}=5 \%\right.$, $\tau^{2}=0.01, \chi^{2}=4.20$ ) (Figure 3).

With regards to the incidence of adverse events, there were no differences between the groups (pooled $O R=1.12, C I_{95 \%}=0.66$ to $1.91, p=0.67, Z=0.43$ ). Figure 4 depicts the metaanalysis of the adverse events subgroups (stimulation-induced, general surgical, neurological complications, and hardware-related). Accuracy of target electrode placement was reported in four studies, where it was similar in both groups. $16,19-21$

\section{Discussion}

This systematic review and metaanalysis has shown that in patients with PD the clinical outcomes and adverse effects after STN-DBS insertions performed under GA were similar to those performed under LA. There was no significant difference in targeting accuracy between groups. In addition, successful localization of the target nuclei was feasible under GA using intraoperative MER. However, all the studies included in the metaanalysis were retrospective cohort studies with small numbers in each group. Currently, there are only poor-quality data suggesting a trend toward improved postoperative motor outcomes with UPDRS scoring with LA, though this was not statistically significant. However, the small sample size in the included studies might have affected the statistical significance.
Insertion of DBS electrodes is commonly performed under LA with or without sedation to facilitate intraoperative neurophysiological testing. Intraoperative localization of the STN is considered indispensable despite preoperative image-based target planning. This could be due to brain displacement occurring as a result of cerebrospinal fluid leakage during surgery or accumulation of subdural air with burr holes, as well as the use of stiff microelectrode needles. In addition to the use of MER for target localization, the advantages of surgery performed while the patient is awake are that it allows for evaluation of the intraoperative stimulation-induced improvement in symptoms and also helps to detect stimulation-induced adverse effects. ${ }^{2}$ However, the disadvantages of the LA technique with an awake patient include restlessness, fatigue, anxiety, and agitation due to the longduration surgery and probable exacerbation of symptoms in the "off-medication" state.

In contrast to the conventional practice of LA for DBS insertion, the procedure under GA allows patients to continue their preoperative antiparkinsonian medications and offers increased patient comfort and acceptance during surgery. Nevertheless, it can interfere with MER by suppressing or abolishing spontaneous neuronal firing and impede evaluation of the clinical benefits of intraoperative stimulation. In addition, the patient cannot report subjective adverse effects, such as paresthesia or abnormal motor activity due to stimulation of adjacent structures. ${ }^{24}$

Improved understanding of neuronal activity during STN has enabled patients to undergo STN-DBS under GA with intraoperative MER guidance. Though few studies reported reduced baseline background noise from STN-MER, many studies ${ }^{10,19,22}$ have shown that localization of STN using intraoperative electrophysiological recordings is possible with a variety of inhalational and intravenous anesthetic agents. In addition, they also reported good clinical outcomes. Studies comparing GA and

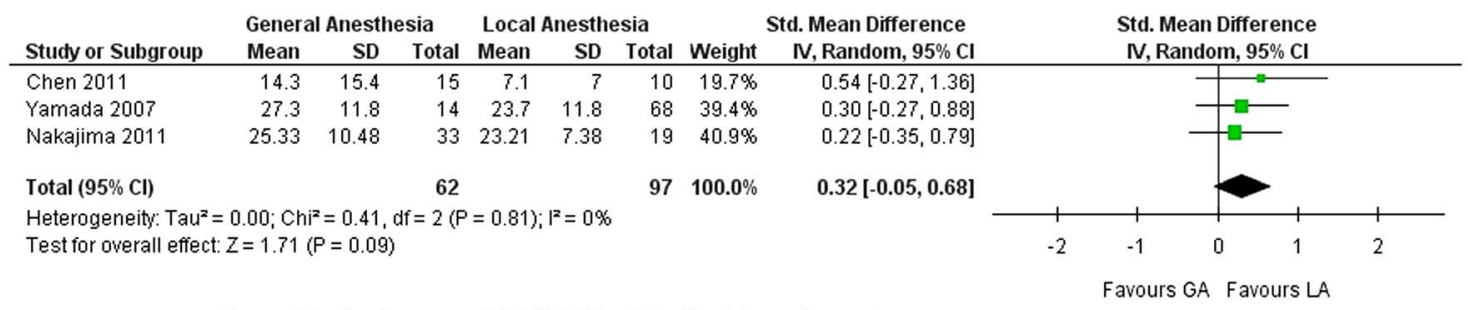

Forest Plot for Outcome (UPDRS III), CI - Confidence Interval, IV - Inverse Variance

Figure 2: Forest plot for UPDRS III score improvement. 


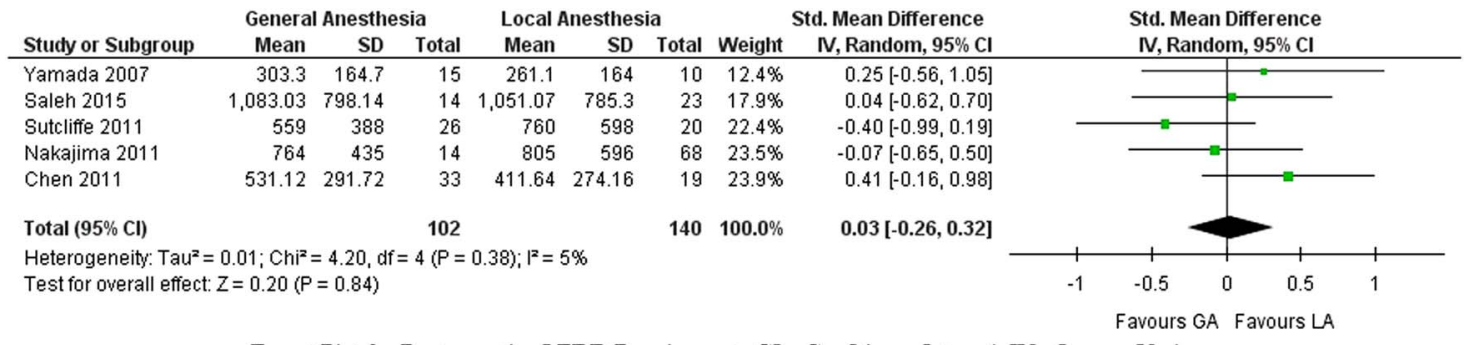

Forest Plot for Postoperative LEDD Requirement, CI - Confidence Interval, IV - Inverse Variance

Figure 3: Forest plot for postoperative LEDD requirement.

LA groups ${ }^{16,19,20,22}$ reported successful target localization using MER with no significant differences. However, it was difficult to compare the quality of MER between groups because the details of neuronal activity, number of electrode passes, depth of STN, and changes in target tracts and coordinates were not reported uniformly across these studies.

Though there are ongoing studies to address the best anesthetic technique for MER, many clinicians are doing DBS insertion under GA without MER. Recent advances in imaging techniques, especially the intraoperative MRI-CT techniques, have enabled DBS insertions to be performed under GA without MER. In some cases, the whole procedure-including targeting, lead placement, and confirmation of electrode location-is now performed under GA with iMRI. The advantages of this technique include real-time imaging, reduced duration, reduced number of penetrations for electrode placement, and early detection of such complications as intracerebral hemorrhage. Recent studies ${ }^{6,7}$ have shown that iMRI
DBS implantation has comparable outcomes to those with framebased MER-guided surgery. However, these are small case series, and prospective studies are needed to accurately compare study outcomes.

Though there are many studies with DBS insertion under $\mathrm{GA}$, it is difficult to translate the data regarding clinical outcomes from these studies due to the absence of a control group. The reported outcomes evaluated in the literature include either clinical measures such as UPDRS I to IV, Hoehn and Yahr staging, Schwab and England scores, reduction in LEDD, or those related to successful target localization (i.e., image guidance or MER). Among these, UPDRS III has been the most commonly used clinical outcome measure and has been shown to correlate well with the accuracy of target placement using either image or MER guidance. Thus, we utilized UPDRS III and LEDD reduction in our study for comparison between the GA and LA groups.

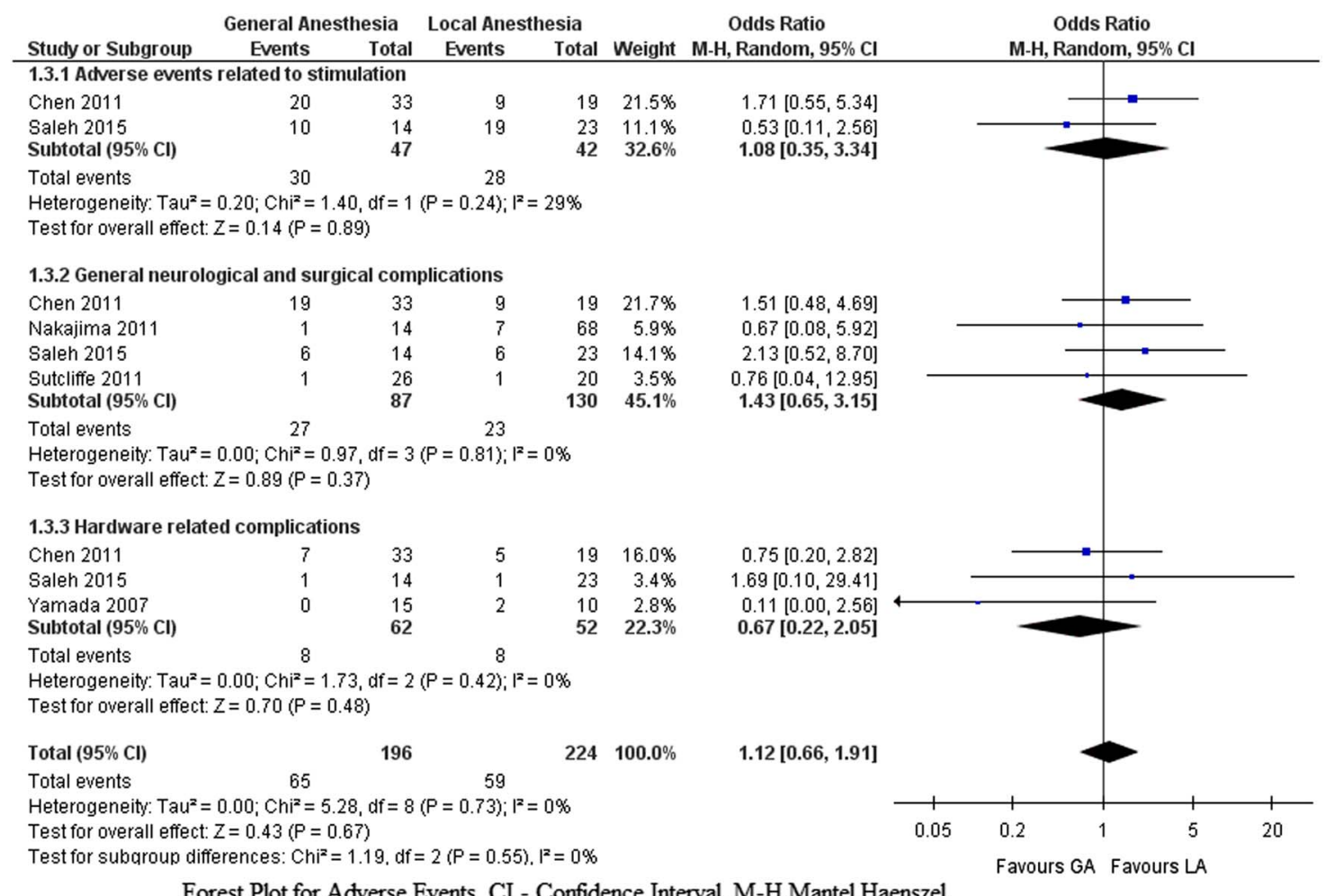

Figure 4: Forest plot for adverse events. 


\section{Clinical Implications ANd Future directions}

In view of the retrospective nature of the available studies and the heterogeneity among the reported clinical outcomes, this metaanalysis could not definitively answer the question of whether DBS under GA is comparable to that with LA. However, our study has laid down a platform for further research in this field. The use of GA will provide higher levels of acceptance to subgroups of patients where LA may not be a realistic option. Hence, there is a need for a prospective randomized controlled study with adequate power to provide the evidence for comparable clinical outcomes with GA for STN-DBS insertion in PD patients. The outcome reporting methodology should also be improved to ensure comparability among studies. Recent guidelines published by the Movement Disorder Society have provided a framework for data presentation in order to facilitate the comparison and interpretation of results across clinical DBS studies in PD (Guide4DBS-PD). ${ }^{15}$ The preferred reporting of postoperative details include time of assessment relative to implantation, levodopa requirements, stimulation settings, UPDRS scores (at least III), and adverse events.

\section{LIMITATIONS}

We acknowledge several limitations of our study, mainly due to the retrospective nature of the included studies. The type of anesthesia was not randomized in any of them. Patient assignments to the GA or LA group depended primarily on patient comorbidities, and in most of the studies patients who could not tolerate an awake procedure had GA. Hence, there was a huge selection bias, a major confounding factor for our study. Target accuracy was not reported in all the studies. The postoperative follow-up times might have been different, as these studies were retrospective in nature. In addition, the results from many of the reported studies had large confidence intervals, indicating possible small sample sizes in the primary studies. This would have affected the final results of our metaanalysis. Finally, we did not assess publication bias, as more than 10 studies are usually required to detect funnel plot asymmetry.

\section{Conclusions}

This systematic review and metaanalysis demonstrates that at present there are no good-quality data to suggest equivalence of GA to LA in terms of safety and efficacy during STN-DBS insertion in patients with PD, with some factors trending toward LA. A large prospective randomized controlled trial is required for adequate validation of GA during STN-DBS insertion in patients with PD.

\section{Disclosures}

The authors hereby declare that they have no conflicts of interest to disclose.

\section{Statement of Authorship}

VS helped with study design, literature review, data entry, data analysis, and writing the manuscript. NCR helped with literature review, data entry, and writing the manuscript. JM helped with literature search, data collection, and writing the manuscript.
ME helped with literature search and writing the manuscript. PM helped to write the manuscript. LV helped with study design, data analysis, and writing the manuscript. All the authors approved the final manuscript.

\section{SUPPLEMENTARY MATERIALS}

To view the supplementary materials for this article, please visit https://doi.org/10.1017/cjn.2017.224.

\section{REFERENCES}

1. Limousin P, Krack P, Pollak P, et al. Electrical stimulation of the subthalamic nucleus in advanced Parkinson's disease. N Engl J Med. 1998;339(16):1105-11.

2. Houeto JL, Welter ML, Bejjani PB, et al. Subthalamic stimulation in Parkinson disease: intraoperative predictive factors. Arch Neurol. 2003;60(5):690-4.

3. Maltête D, Navarro S, Welter ML, et al. Subthalamic stimulation in Parkinson disease: with or without anesthesia? Arch Neurol. 2004;61(3):390-2.

4. Lin SH, Chen TY, Lin SZ, et al. Subthalamic deep brain stimulation after anesthetic inhalation in Parkinson disease: a preliminary study. J Neurosurg. 2008;109(2):238-44.

5. Starr PA, Martin AJ, Ostrem JL, Talke P, Levesque N, Larson PS. Subthalamic nucleus deep brain stimulator placement using high-field interventional magnetic resonance imaging and a skull-mounted aiming device: technique and application accuracy. J Neurosurg. 2010;112(3):479-90.

6. Ostrem JL, Ziman N, Galifianakis NB, et al. Clinical outcomes using ClearPoint interventional MRI for deep brain stimulation lead placement in Parkinson's disease. J Neurosurg. 2016;124(4): 908-16.

7. Chabardes S, Isnard S, Castrioto A, et al. Surgical implantation of STN-DBS leads using intraoperative MRI guidance: technique, accuracy, and clinical benefit at 1-year follow-up. Acta Neurochir (Wien). 2015;157(4):729-37.

8. Hertel F, Züchner M, Weimar I, et al. Implantation of electrodes for deep brain stimulation of the subthalamic nucleus in advanced Parkinson's disease with the aid of intraoperative microrecording under general anesthesia. Neurosurgery. 2006; 59(5):E1138

9. Harries AM, Kausar J, Roberts SA, et al. Deep brain stimulation of the subthalamic nucleus for advanced Parkinson disease using general anesthesia: long-term results. J Neurosurg. 2012;116(1): 107-13.

10. Moll CK, Payer S, Gulberti A, et al. STN stimulation in general anaesthesia: evidence beyond "evidence-based medicine." Acta Neurochir Suppl. 2013;117:19-25.

11. Fluchere F, Witjas T, Eusebio A, et al. Controlled general anaesthesia for subthalamic nucleus stimulation in Parkinson's disease. J Neurol Neurosurg Psychiatry. 2014;85(10):1167-73.

12. Moher D, Liberati A, Tetzlaff J, Altman DG, PRISMA Group. Preferred reporting items for systematic reviews and meta-analyses: the PRISMA statement. PLoS Med. 2009;6(7): e1000097.

13. Wells GA, Shea B, O'Connell D, et al. The Newcastle-Ottawa Scale (NOS) for Assessing the Quality of Nonrandomised Studies in Meta-Analyses. Ottawa: Ottawa Hospital Research Institute; 2014, Available at: http://www.ohri.ca/programs/clinical_ epidemiology/oxford.asp.

14. Goetz CG, Tilley BC, Shaftman SR, et al. Movement Disorder Society-sponsored revision of the Unified Parkinson's Disease Rating Scale (MDS-UPDRS): scale presentation and clinimetric testing results. Mov Disord. 2008;23(15):2129-70.

15. Vitek JL, Lyons KE, Bakay R, et al. Standard guidelines for publication of deep brain stimulation studies in Parkinson's disease (Guide4DBS-PD). Mov Disord. 2010;25(11):1530-7.

16. Yamada K, Gotoa S, Kuratsua J, et al. Stereotactic surgery for subthalamic nucleus stimulation under general anesthesia: a retrospective evaluation of Japanese patients with Parkinson's disease. Parkinsonism Relat Disord. 2007;13(2):101-7. 
17. DerSimonian R, Laird N. Meta-analysis in clinical trials. Control Clin Trials. 1986;7(3):177-87.

18. Higgins JP, Thompson SG, Deeks JJ, Altman DG. Measuring inconsistencies in meta-analyses. BMJ. 2003;327(7414):557-60.

19. Lefaucheur JP, Gurruchaga JM, Pollin B, et al. Outcome of bilateral subthalamic nucleus stimulation in the treatment of Parkinson's disease: correlation with intra-operative multi-unit recordings but not with the type of anaesthesia. Eur Neurol. 2008;60(4):186-99.

20. Chen SY, Tsai ST, Lin SH, et al. Subthalamic deep brain stimulation in Parkinson's disease under different anesthetic modalities: a comparative cohort study. Stereotact Funct Neurosurg. 2011;89(6): 372-80.

21. Nakajima T, Zrinzo L, Foltynie T, et al. MRI-guided subthalamic nucleus deep brain stimulation without microelectrode recording: can we dispense with surgery under local anaesthesia? Stereotact Funct Neurosurg. 2011;89(5):318-25.

22. Sutcliffe AJ, Mitchell RD, Gan YC, Mocroft AP, Nightingale P. General anaesthesia for deep brain stimulator electrode insertion in Parkinson's disease. Acta Neurochir. 2011;153(3): 621-7.

23. Saleh S, Swanson KI, Lake WB, Sillay KA. Awake neurophysiologically guided versus asleep MRI-guided STN-DBS for Parkinson disease: a comparison of outcomes using levodopa equivalents. Stereotact Funct Neurosurg. 2015;93(6):419-26.

24. Lettieri C, Rinaldo S, Devigili G, et al. Deep brain stimulation: subthalamic nucleus electrophysiological activity in awake and anesthetized patients. Clin Neuropysiol. 2012;123(12): 2406-13. 